\title{
COMPARISON OF SPIROMETRIC PULMONARY FUNCTION IN SUBJECTS WITH APPLE AND PEAR SHAPE FAT DISTRIBUTION
}

\section{Krina Chheda ${ }^{* 1}$, Jaimala Shetye ${ }^{2}$, Amita Mehta ${ }^{3}$.}

${ }^{* 1}$ Post graduate student, PT school and Centre, Seth GSMC and KEMH, Parel, Mumbai, India.

${ }^{2}$ Associate Professor, PT school and centre, Seth GSMC and KEMH, Parel, Mumbai, India.

${ }^{3}$ Professor and Head, PT school and centre, Seth GSMC and KEMH PT School, Parel, Mumbai, India.

\section{ABSTRACT}

Background: The pattern of obesity as decided by body fat distribution is an important predictor of adverse health effects such as diabetes, hypertension, hyperlipidaemia and coronary events. Waist hip ratio has been correlated with cardiovascular risk. Obesity is been known to cause restrictive respiratory impairment however; the effect of body fat distribution on the respiratory system is often underappreciated and limited evidence is available on spirometric pulmonary function in subjects with different body fat distribution. Hence here is a need to know weather pattern of obesity affects pulmonary function.

Objectives: 1) To measure Waist Hip ratio (WHR) of subjects having BMI of more than $23 \mathrm{~kg} / \mathrm{m}^{2}$ and based on this form two groups, one with apple and the other with pear shape fat distribution 2) To measure FVC and FEV1 in subjects of the above two groups.3) To compare FVC, FEV1 and \%FEV1/FVC in above two groups.

Methodology: In this comparative study a total of 182 subjects comprising of 91 subjects of Apple shaped and Pear shaped each were recruited in a period of 6 months.

Study Settings: The study was conducted in the outpatient Physiotherapy department of a tertiary care hospital. The subjects in the study belonged to age group of 18-40 years. The mean age of the enrolled subjects was 29 years.

Outcome measure: 1.FVC (L) 2. \%FEV1/FVC

Results: The present study provides the evidence that FVC and \%FEV1/FVC values are not statistically different in apple and pear shaped fat distribution individuals. Although both apple and pear shaped individuals showed \%FEV1/FVC value more than 70\% predicted, apple shaped individuals showed greater obstructive tendency i.e. reduced flow rates as compared to pear shaped individuals. Also more individuals of apple shaped showed restrictive pattern as compared to pear shaped.

Conclusion: There was no statistically significant difference in the pulmonary function test in the two groups but there is a possibility of subclinical reduction in pulmonary function more in apple shaped than in pear shaped individuals

KEY WORDS: Spirometric Pulmonary functions, Apple shaped and Pear shaped body fat distribution.

Address for correspondence: Krina Chheda, Post graduate student, PT school and Centre, Seth GSMC and KEMH, Parel, Mumbai-400012, India. E-Mail: krinachheda26@gmail.com

Access this Article online

Quick Response code

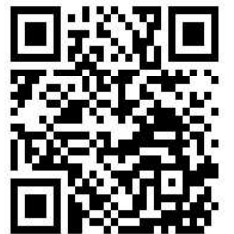

DOI: $10.16965 /$ ijpr.2020.133

Journal Information

International Journal of Physiotherapy and Research

ISSN (E) 2321-1822 | ISSN (P) 2321-8975

https://www.ijmhr.org/ijpr.html

DOI-Prefix: https://dx.doi.org/10.16965/ijpr

(cc) BT-Mo-Bi

\section{Article Information}

Received: 21 Apr 2020

Peer Review: 21 Apr 2020

Revised: None
Accepted: 15 May 2020

Published (O): 11 Jun 2020

Published (P): 11 Jun 2020 


\section{INTRODUCTION}

Obesity is a metabolic disease that impairs health-related quality of life and is a major cause of morbidity and mortality. It is also known to be strongly linked with respiratory symptoms and diseases [1]. Body mass index (BMI) is a simple index of weight-for-height that is commonly used to classify underweight, overweight and obesity in adults. WHO defines BMI as the weight in kilograms divided by the square of height in meters $\left(\mathrm{kg} / \mathrm{m}^{2}\right)$. The International Association for the Study of Obesity (IASO), the International Obesity Task Force (IOTF) and the WHO proposed BMI cut-points $23.0-24.9 \mathrm{~kg} /$ $\mathrm{m}^{2}$ for being overweight and $\geq 25.0 \mathrm{~kg} / \mathrm{m}^{2}$ for obesity in adult Asians [2,3]. (Table1)

Body fat distribution is an important predictor of adverse health events such as diabetes, hypertension, hyperlipidaemia and coronary events, Waist-to hip ratio (WHR) measure is used to determine body fat distribution [4]. Two distinct patterns of obesity are recognized in the general population. Android or apple shape in which there is deposition of body fat predominantly in upper body i.e. visceral deposits at the level of the waist and subcutaneous deposits on the back and gynoid or pear shaped in which the fat is deposited mainly in the lower body, i.e. on the thighs and buttocks [5].

Spirometry measures lung volume, capacity, rate of flow, and gas exchange. Forced vital capacity is the primary indicator of lung volume. A reduction in FVC is diagnostic of restrictive impairment. FEV1 is the volume of air exhaled in the first second of forced expiration and is influenced by lung volume and airflow obstruction. The ratio of FEV 1 and FVC as percentage is diagnostic of obstructive pulmonary impairment. During forced expiration a normal individual can exhale $75 \%$ of FVC in first second of exhalation [6].

Obesity is associated with reductions in lung volumes, particularly forced vital capacity (FVC) and \%FEV1/FVC. Considering the respiratory comorbidity in obese individuals, we propose that the effect of fat distribution in obese may have a differential effect on FVC and FEV1 [7].

\section{METHODOLOGY}

Total 182 samples were recruited by purposive sampling. It is a one-time assessment study, 25 minutes per subject. Institutional ethic committee approval was taken. All subjects satisfying the inclusion criteria in age group $18-40$ years with $\mathrm{BMI}$ above $23 \mathrm{~kg} / \mathrm{m}^{2}$ (overweight and obese individuals) were included in the study. The informed written consent was obtained.

\section{Study procedure}

1. Body weight was measured to the nearest $0.10 \mathrm{~kg}$, without footwear with participants lightly dressed using a portable beam scale. Body height was measured to the nearest millimetre in bare feet using a wall mounted measuring tape with the subjects back and heels touching the wall. BMI was calculated as body weight $(\mathrm{kg})$ divided by height $(\mathrm{m})$ squared.

2. Waist circumference $(\mathrm{cm})$ was measured from the approximate midpoint between the lower margin of the last palpable rib and the top of the iliac crest (WHO, 2008).

3. The hip circumference $(\mathrm{cm})$ was measured around the widest portion of the buttocks. Waist hip ratio was calculated.

4. WHR value was used to determine body type. (WHR $\geq 0.88$ in men and $\geq 0.81$ in females was considered as apple shaped and the remaining were considered as pear shaped (Table 2) [3].

5. Based on the above categorization two groups were obtained i.e. apple and pear fat distribution. PFT was recorded with DT spiro masteros machine in standing position. The predicted Values of FVC and FEV1 given by the spirometer machine were recorded.

6. Three readings of FVC and FEV1 were taken and the best of three values was selected for the study. The FVC and FEV1 observed values were noted and \%FEV1/FVC ratio was calculated.

Table 1: Obesity classification for Asian population.

\begin{tabular}{|c|c|}
\hline $\begin{array}{c}\text { BMI } \\
\left(\mathrm{kg} / \mathrm{m}^{2}\right)\end{array}$ & $\begin{array}{c}\text { Asian population } \\
\text { (WHO) }\end{array}$ \\
\hline $23-24.9$ & Overweight \\
\hline
\end{tabular}

Table 2: WHR values to classify into apple and pear shape fat distribution.

\begin{tabular}{|c|c|c|}
\hline Waist Hip Ratio & Apple shape & Pear shape \\
\hline Male & $\geq 0.88$ & $<0.88$ \\
\hline Female & $\geq 0.81$ & $<0.81$ \\
\hline
\end{tabular}


Fig. 1: Measurement of PFT using DT spiro (masteros) machine.

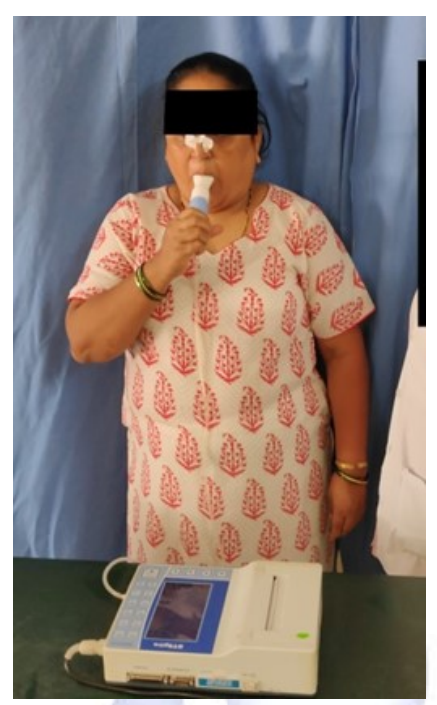

Statistical analysis: Data was entered in Microsoft excel and analysed using SPSS software version 23. Subjects were screened until a total of 182 participants who met the study criteria were recruited in study such that 91 participants were obtained in the two groups. The mean and standard deviation of observed FVC and FEV1 and \%FEV1/FVC was calculated for both the groups. Normality of the data was measured using Shapiro Wilk normality test and the data collected was found to be not normally distributed. Comparison of FVC and \%FEV1/FVC between apple and pear shape fat distribution was performed using non-parametric Mann Whitney test. The test was carried out at 5\% significance. Confidence interval $(\mathrm{Cl})$ of $95 \%$ was chosen. $P$ value $<0.05$ was considered to be statistically significant.

\section{RESULTS}

This comparative study recruited 182 samples. The mean BMI of both groups was in range of Grade one obese $25.00-29.9 \mathrm{~kg} / \mathrm{m}^{2}$. The mean WHR of apple and pear shape individuals was 0.88 and 0.78 respectively. The comparison among the two groups is seen in table 3 .

Table 4 shows the mean predicted values of FVC for apple shaped are $2.76 \mathrm{~L}$ and for pear shape are $2.77 \mathrm{~L}$. The mean of observed values of FVC was $2.59 \mathrm{~L}$ in both the groups however they differed in standard deviation.Table 5 shows the median values of FVC for apple and pear shaped groups that indicate nearly $50 \%$ of the subjects have values below $2.60 \mathrm{~L}$ in apple shaped group and below $2.68 \mathrm{~L}$ in pear shaped group.
Two groups were compared using Mann Whitney test and results were non-significant ( $p$ value $=0.534$ )

Table3: Baseline categorical data.

\begin{tabular}{|c|c|c|}
\hline & $\begin{array}{c}\text { Apple shaped } \\
\text { (Mean } \pm \text { SD) }\end{array}$ & $\begin{array}{c}\text { Pear shaped } \\
\text { (Mean } \pm \text { SD) }\end{array}$ \\
\hline Males (count) & 17 & 12 \\
\hline Females (count) & 74 & 69 \\
\hline Age (years) & $27.27 \pm 6.39$ & $26.56 \pm 5.96$ \\
\hline Weight (kg) & $71.55 \pm 13.96$ & $69.24 \pm 9.39$ \\
\hline Height (cm) & $159.16 \pm 8.81$ & $158.93 \pm 8.05$ \\
\hline BMI kg/m ${ }^{2}$ & $28.21 \pm 4.17$ & $27.50 \pm 3.81$ \\
\hline $\begin{array}{c}\text { Waist } \\
\text { circumference(cm) }\end{array}$ & $93.44 \pm 10.31$ & $86.22 \pm 6.99$ \\
\hline $\begin{array}{c}\text { Hip circumference } \\
\text { (cm) }\end{array}$ & $106.27 \pm 10.22$ & $109.45 \pm 8.56$ \\
\hline WHR & $0.88 \pm 0.05$ & $0.78 \pm 0.04$ \\
\hline
\end{tabular}

Table 4: Pulmonary function in two groups.

\begin{tabular}{|c|c|c|}
\hline Value & $\begin{array}{c}\text { Apple shape } \\
\text { (Mean } \pm \text { SD) }\end{array}$ & $\begin{array}{c}\text { Pear shape } \\
\text { (Mean } \pm \text { SD) }\end{array}$ \\
\hline Predicted FVC (L) & $2.76 \pm 0.52$ & $2.77 \pm 0.44$ \\
\hline Observed FVC (L) & $2.59 \pm 0.93$ & $2.59 \pm 0.67$ \\
\hline Predicted FEV1 (L) & $2.32 \pm 0.42$ & $2.34 \pm 0.39$ \\
\hline Observed FEV1 (L) & $2.11 \pm 0.73$ & $2.24 \pm 0.66$ \\
\hline Observed \%FEV1/FVC & $83.2 \pm 16.39$ & $87.3 \pm 14.31$ \\
\hline
\end{tabular}

Table 5: FVC characteristics in two groups.

\begin{tabular}{|c|c|c|c|}
\hline & & \multicolumn{2}{|c|}{ Obesity type } \\
\hline \multirow{4}{*}{} & & Apple & Pear \\
\cline { 2 - 4 } & Count (N) & $\mathrm{N}=91$ & $\mathrm{~N}=91$ \\
\cline { 2 - 4 } & Minimum & $0.89(\mathrm{~L})$ & $0.74(\mathrm{~L})$ \\
\cline { 2 - 4 } & Maximum & $6.93(\mathrm{~L})$ & $4.04(\mathrm{~L})$ \\
\cline { 2 - 4 } $\begin{array}{c}\text { Best of 3 } \\
\text { FVC(L) }\end{array}$ & Percentile 05 & $1.17(\mathrm{~L})$ & $1.24(\mathrm{~L})$ \\
\cline { 2 - 4 } & Percentile 25 & $2.10(\mathrm{~L})$ & $2.31(\mathrm{~L})$ \\
\cline { 2 - 4 } & Median & $2.60(\mathrm{~L})$ & $2.68(\mathrm{~L})$ \\
\cline { 2 - 4 } & Percentile 75 & $3.00(\mathrm{~L})$ & $2.97(\mathrm{~L})$ \\
\cline { 2 - 4 } & Percentile 95 & $4.24(\mathrm{~L})$ & $3.77(\mathrm{~L})$ \\
\cline { 2 - 4 } & Mean & $2.59(\mathrm{~L})$ & $2.59(\mathrm{~L})$ \\
\cline { 2 - 4 } & Standard Deviation & $0.93(\mathrm{~L})$ & $0.67(\mathrm{~L})$ \\
\hline
\end{tabular}

Table 6: Characteristics of FEV1 in two groups.

\begin{tabular}{|c|c|c|c|}
\hline & & \multicolumn{2}{|c|}{ Obesity type } \\
\hline \multirow{4}{*}{} & & A & P \\
\cline { 2 - 4 } & Count & $\mathrm{N}=91$ & $\mathrm{~N}=91$ \\
\cline { 2 - 4 } & Minimum & $0.57(\mathrm{~L})$ & $0.53(\mathrm{~L})$ \\
\cline { 2 - 4 } & Maximum & $4.20(\mathrm{~L})$ & $3.77(\mathrm{~L})$ \\
\cline { 2 - 4 } $\begin{array}{c}\text { Best of 3 } \\
\text { FEV1 (L) }\end{array}$ & Percentile 05 & $0.86(\mathrm{~L})$ & $1.01(\mathrm{~L})$ \\
\cline { 2 - 4 } & Percentile 25 & $1.60(\mathrm{~L})$ & $1.92(\mathrm{~L})$ \\
\cline { 2 - 4 } & Median & $2.20(\mathrm{~L})$ & $2.28(\mathrm{~L})$ \\
\cline { 2 - 4 } & Percentile 75 & $2.45(\mathrm{~L})$ & $2.61(\mathrm{~L})$ \\
\cline { 2 - 4 } & Percentile 95 & $3.32(\mathrm{~L})$ & $3.33(\mathrm{~L})$ \\
\cline { 2 - 4 } & Mean & $2.11(\mathrm{~L})$ & $2.24(\mathrm{~L})$ \\
\cline { 2 - 4 } & Standard Deviation & $0.73(\mathrm{~L})$ & $0.66(\mathrm{~L})$ \\
\hline
\end{tabular}


Table 7: Frequency distribution of flow pattern i.e. \%FEV1/FVC.

\begin{tabular}{|c|c|c|c|c|c|}
\hline \multicolumn{2}{|c|}{} & \multicolumn{2}{|c|}{ Obesity type } & \multirow{2}{*}{ Total } & \multirow{2}{*}{ P value } \\
\cline { 3 - 4 } & Count & A & P & & \\
\hline \multirow{3}{*}{ Obstructive } & $\begin{array}{c}\text { \% of subjects with } \\
\text { \%FEV1/FVC less than 70\% }\end{array}$ & $75.00 \%$ & $25.00 \%$ & $100 \%$ & \multirow{2}{*}{0.036 (S) } \\
\cline { 2 - 4 } & $\begin{array}{c}\text { \% of obstructive individuals } \\
\text { among 91 of each group }\end{array}$ & $13.20 \%$ & $4.40 \%$ & \multirow{2}{*}{$8.80 \%$} & \\
\hline
\end{tabular}

(S= Significant)

Table 4 the predicted values of FEV1 are $2.32 \mathrm{~L}$ for apple shaped and for pear shaped is $2.34 \mathrm{~L}$. The observed value of FEV1 is $2.11 \mathrm{~L}$ for apple shaped and 2.24L for pear shaped. In table 6 the median values of FEV1 for apple and pear shaped groups indicate that nearly $50 \%$ of the subjects have values below $2.20 \mathrm{~L}$ in apple shaped group and below $2.28 \mathrm{~L}$ in pear shaped group. Two groups were compared using Mann Whitney test and results were non-significant ( $p$ value $=0.194$ )

\% FEV1 /FVC observed value for apple shaped is $83.2 \%$ and pear shaped is $87.3 \%$. Table 7 shows frequency distribution of apple and pear shaped subjects with respect to \%FEV1/FVC shows that 12 out of 91 samples of apple shape and only 4 out of 91 of pear shaped show obstruction. It is seen that out of 91 individuals of each group $13.2 \%$ of apple shaped show obstruction and only $4.4 \%$ of pear shaped individuals show obstruction.

\section{DISCUSSION}

The median values of FVC and FEV1 of both the groups are close to their predicted values. The FVC, \%FEV1/FVC values between the two groups were compared and the results were nonsignificant. It is observed that pear shaped show better flow as compared to apple shape. It implies that apple shaped fat distribution among over weight and obese individuals have significantly more individuals showing obstructive pattern as compared to those with pear shaped fat distribution.

Ajmani et al, Devershetty, Mohammed Al Ghobain in their study showed that FVC and FEV1 values did not show any significant changes in high and low BMI group [8-10]. It was found that female subjects tend to have lower PFT values as their respiratory muscle endurance and chest wall compliance is lower than that of males and that spirometric abnormalities in subjects of mild to moderate obesity

represent restrictive defect whereas subjects with severe and morbid obesity show air flow obstruction [9]. Our study results are in accordance to above studies.

G. K. Sudhir found mixed pattern of pulmonary function with 7 subjects which was significantly higher in the obese group compared with normal. Obstructive pattern of pulmonary function was seen only among the overweight and obese groups with 8 subjects having this pattern out of 100, which was significant with obese group [11]. As majority of the subjects in our study were in group of grade 1 obesity we found normal pattern (91.2\% of subjects).

Harik-Khan et al in their gender based study showed that there is an association of fat distribution and pulmonary function using waist hip ratio and they also reported no inverse association of FEV1 and waist hip ratio in females $[12,13,14]$. Sable et al, Rasslan et al found that WHR is a more important determinant of pulmonary function in women than in men. WHR is a significant predictor of FEV1 in women only $[15,16]$. Our study had majority of female population (78.57\%) due to availability this may explain poor correlation in our subjects.

Also, the studies conducted in Children have study results similar to our study. Khan Sara found that in girls adiposity was not associated with poor lung function [17]. Boran et al concluded in his study that no correlation was observed between pulmonary function parameters and anthropometric measurements pulmonary function test parameters of the mildly obese children were similar to those of the normal weight children however 3 out of 80 children had an obstructive pattern [18].

In contrast to our study Alselevany et al showed FVC and FEV1 were significantly lower in central obesity group compared to periphery obesity group while FEV1\% in central obesity 
group was higher than peripheral obesity group but the difference was statistically not significant [19]. Canoy et al analysed the association of WHR with FVC and FEV1 in both men and women and found a significant inverse association however the study population was from age group of 45-79 years [20].

Also the study conducted by Ochs-Balcom et al, Saxena et al, Collins et al, Steele et al [21-24] reported that WHR had significant negative relations with FVC and FEV1 which contrasts our study results.

It is well established that obesity decreases both lung and chest compliance and hence decreases the lung volumes and capacities. There is an increase in resistance to outflow of air in obesity [25]. The pattern of pulmonary function worsens with the degree of obesity moving from a restrictive pattern in mild to moderate obesity with both FEV 1 and FVC reduced and \%FEV1/FVC ratio being normal to an obstructive pattern in severe and morbid obesity with significant decrease in FEV 1 and \%FEV1/FVC ratio being decreased [11].

As the airways undergo narrowing and close at a higher than normal closing volumes due to its hyper-responsiveness and increased smooth muscle tone induced by obesity we get to see mixed pattern. The changes seen with initial weight gain is that there is relative increase in muscle strength and so pulmonary function initially increases but further increase in body weight reduces lung function due to obesity [26]. Abdominal obesity causes mechanical effects because of reductions in chest wall compliance, respiratory muscle strength and function, lung volumes and peripheral airway size. Abdominal fat may limit lung expansion by altering pressure-volume characteristics of the thorax and restrict the descent of the diaphragm. The lung bases show reduced ventilation which can lead to the closure of peripheral lung units, ventilation to perfusion ratio abnormalities and arterial hypoxemia. The work of breathing is increased and expiratory reserve volume is reduced. These changes can also lead to reduced forced vital capacity (FVC). Abdominal fat compresses the lungs and diaphragm resulting in lower FEV1, FVC measurements [1]. Fat deposits between the muscles and the ribs may also decrease chest wall compliance thereby increasing the metabolic demands and workload of breathing in the obese even when at rest. It is plausible that hypoxia due to chronic obstruction may then trigger the sympathetic nervous system activity leading to increased pulmonary vascular resistance. Consequently, the capacity for air in the lungs decreases. These changes are seen when abdominal obesity shows restrictive pattern.

There is another mechanism by which adiposity causes reduced pulmonary functions. It is linked with the fact that adiposity is a low-grade inflammatory condition and is associated to insulin resistance. Fat cells act as a type of endocrine cell, and adipose tissue as an endocrine organ. Central type obesity can lead to an imbalance in the production of several metabolic products, adipokines and cytokines. It has been suggested that visceral adipose tissue influences circulating concentrations of interleukin-6, tumour necrosis factor-a, resistin, free fatty acids, leptin and adiponectin (fat cell-derived products). These cytokines may cause systemic inflammation which is thought to be associated with reduced pulmonary function. Also the release of leptin an inûammatory marker on the lung tissue slightly effects on airway diameter causes obstructive pattern. Obesity is a pro inflammatory condition and hence could contribute to airway hyper responsiveness leading to obstruction [27].

There are gender differences in the pattern of fat distribution. Males tend to accumulate a much higher proportion of body fat in the viscera so their WHR is likely to be strongly dependent on intra-abdominal fat depots which impair the work of the diaphragm in exhaling air from the lungs. Contrast to this in females.

WHR expresses primarily the subcutaneous adiposity, an aspect of fat distribution having little or no bearing on the work of the diaphragm [15]. Since our study included majority of female subjects this gender impact of fat could play a major role.

This study aimed to compare spirometric pulmonary functions in apple and pear shaped fat distribution. The results of the study revealed that FVC and \%FEV1/FVC are not different in two groups statistically. 


\section{CONCLUSION}

The present study provides the evidence that FVC and \%FEV1/FVC values are not different in apple and pear shaped fat distribution individuals. However, Apple shaped individuals show greater obstructive tendency i.e. reduced flow rates as compared to pear shaped individuals. Also there were more number of apple shaped subjects with obstructive and restrictive pattern as compared to those in pear shaped subjects. It is clinically important to document pulmonary function while evaluating a subject for weight loss program. Presence of obstruction may limit the exercise performance in them.

\section{ABBREVIATIONS}

BMI- Body Mass Index.

WHR- Waist Hip Ratio.

WC- Waist circumference.

FVC- Forced Vital capacity.

FEV1- Forced Expiratory Volume in first second

\section{Conflicts of interest: None}

\section{REFERENCES}

[1]. Murugan AT, Sharm G. Obesity and respiratory diseases. Chronic Respiratory Disease 2008; 5: 233242.

[2]. Yajnik C, Yudkin J. Appropriate body-mass index for Asian populations and its implications for policy and intervention strategies. The Lancet.2004;363 (9403):157-163.

[3]. Snehalatha C, Viswanathan V, Ramachandran A. Cutoff Values for Normal Anthropometric Variables in Asian Indian Adults. Diabetes Care. 2003; 26(5):1380-1384.

[4]. McClean K, Kee F, Young I S, ElbornJ S. Obesity and the lung: 1 Epidemiology. Thorax 2008; 63 :649654.

[5]. Ashwell M, Cole T, Dixon A. Obesity: new insight into the anthropometric classification of fat distribution shown by computed tomography. BMJ.1985;290(6483):1692-1694.

[6]. Donna frownfelter, Principles and practice of cardiopulmonary physical therapy. $3^{\text {rd }}$ ed. USA: Elsevier;1996.p.145-152.

[7]. Behazin N, Stephanie B, Jones S, Robert I, Cohen R, Loring $S$. Respiratory restriction and elevated pleural and oesophageal pressures in morbid obesity. J Appl Physiol.2010; 108: 212-218.

[8]. Ajmani S, Sharma A, Kumar N, Sharma V, B G, Pai S. Effect of Abdominal fat on dynamic lung function tests. International Journal of Biomedical and Advance Research. 2012;3(8).
[9]. Devershetty J, Metta S, Uppala S,Kamble G. Effect of obesity on pulmonary function tests in apparently healthy young women. International Journal of Medical Science and Public Health. 2015; 4(11):1519-22.

[10]. Ghobain M. The effect of obesity on spirometry tests among healthy non-smoking adults. BMC Pulmonary Medicine.2012; 12(10):1-5.

[11]. G. K. Sudhir. Correlation of Body Mass Index and Pattern of Pulmonary Function among South Indian Adult Males. International Journal of Recent Trends in Science And Technology. 2014;10(3): 447-450.

[12]. Harik-Khan R, Wise R, Fleg J. The effect of gender on the relationship between body fat distribution and lung function. Journal of Clinical Epidemiology. 2001;54(4):399-406.

[13]. Lazarus R, Gore C, Booth M, Owen N. Effects of body composition and fat distribution on ventilatory function in adults. American Journal of Clinical Nutrition 1998;68:35-41.

[14]. Koziel s, Ulijaszek s, Szklarska a, \&Bielicki t. The effects of fatness and fat distribution on respiratory functions. Annals of Human Biology, JanuaryFebruary 2007; 34(1): 123-131.

[15]. Rasslan Z, Roberto S, Roberto S, Moraes Alves F, Lima Carlos. Evaluation of pulmonary function in class I and II obesity. Jornal Brasileiro de Pneumologia. 2004;30(6):508-514.

[16]. Khan S, Little J, Chen Y. Relationship between Adiposity and Pulmonary Function in School-Aged Canadian Children. Paediatric allergy, Immunology and pulmonology. 2014;27(3):126-132.

[17]. Boran P, Tokuc G, Pisgin B, OktemS,Yegin Z, Bostan O. Impact of obesity on ventilatory function. Jornal de Pediatria 2007;83(2):171-176.

[18]. Baybeen K. Alselevany, Thanoon R. Effect of central obesity on some pulmonary function tests in women. World journal of pharmacy and pharmaceutical sciences ;3(6):1-12.

[19]. Canoy D, Luben R, Welch A, Bingham S, Wareham N, Day $\mathrm{N}$ et al. Abdominal Obesity and Respiratory Function in Men and Women in the EPIC-Norfolk Study, United Kingdom. American Journal of Epidemiology. 2004;159(12):1140-1149.

[20]. Ochs-Balcom H, Grant B, Muti P, Sempos C, Freudenheim J, Trevisan $M$ et al. Pulmonary Function and Abdominal Adiposity in the General Population. Chest. 2006;129(4):853-862.

[21]. Saxena Y, Sidhwani G, Upmanyu R. Abdominal obesity and pulmonary functions in young Indian adults: A prospective study. Indian J physiol pharmacol 2009; 53(4):318-326.

[22]. Collins L, Hoberty P, Walker J, Fletcher E, Peiris A. The Effect of Body Fat Distribution on Pulmonary Function Tests. Chest. 1995;107(5):1298-1302.

[23]. Steele R, Finucane F, Simon J. Griffin, Nicholas J, Wareham, UIf Ekelund. Obesity Is Associated With Altered Lung Function Independently of Physical Activity and Fitness. Obesity. 2008;17: 578-584. 
[24]. Naimark A, Cherniack RM. Compliance of the respiratory system and its components in health and obesity. J Appl Physiol: 1960;15: 377-82.

[25]. Mandal O, Chowdhury S. Effect of distribution of body fat on pulmonary function tests in young adults. IOSR Journal of Dental and Medical Sciences.2018;17(3):74-80.
[26]. Wang S, Sun X, Hsia, et al. The effects of body mass index on spirometry tests among adults in Xi'an, China.Medicine.2017; 96(15):1-5.

How to cite this article:

Krina Chheda, Jaimala Shetye, Amita Mehta. COMPARISON OF SPIROMETRIC PULMONARY FUNCTION IN SUBJECTS WITH APPLE AND PEAR SHAPE FAT DISTRIBUTION. Int J Physiother Res 2020;8(3):3484-3490. DOI: $10.16965 /$ ijpr.2020.133 